\title{
TUBERCULOSE EM GOIÁS - ASPECTOS E PROBLEMAS DA ATIVIDADE DISPENSARIAL
}

\author{
Javan Valle de Mello
}

\begin{abstract}
o autor apresenta dados relativus às atividades do Dispensário de Tuberculose de Goiânia, que dirige, e os compara com os de diferentes órgãos congêneres. Procura demonstrar as condições adversas contra as quais vem atuando seu serviço, impedindo a obtenção de um melhor rendimento da atividade dispensarial.

Os dados apresentados indỉam que a situação, já desfavorável, tende a se agravar, necessitando medidas urgentes de correção, que o autor sugere.
\end{abstract}

No presente trabalho serão apresentados dados estatísticos sumários que refletem a atividade do Dispensário de Tuberculose de Goiânia e são feitas considerações sôbre alguns aspectos da luta antituberculose no Estado de Goiás, que apresentam repercussão negativa nos resultados obtidos pelo Serviço.

\section{MATERIAL}

Os dados numéricos referidos neste trabalho correspondem a pacientes que na grande maioria procuram o Dispensário de Tuberculose (D.T.) espontâneamente, seja por se sentirem doentes, seja por necessitarem da abreugrafia para fins escolares, para posse em empregos e cargos públicos, obtenção de carteiras de saúde etc Uma minoria de pacientes veio ao D.T. "compulsòriamente": são os comunicantes, os reatores-fortes evidenciados em inquéritos tuberculínicos etc.

Os pacientes são divididos em "Distritais" e "Extra-distritais". Os primeiros são os residentes no municipio de Goiânia e os Extra-distritaís nas demais cidades.
São classificados como Virgens de Tratamento (VT) os pacientes que não tenham feito uso de medicação específica. ou que a tenham usado por menos de $\mathbf{3 0}$ dias. Os Provàvelmente Sensíveis (PS) são pacientes que usaram medicação por mais de 30 dias, porém corretamente. Os demais, são classificados como "crônicos', ou Caso Tratado (CT). O prognóstico de recuperação dos VT e PS é muito melhor que dos CT, devido ao problema da resistência bacteriana às drogas, o que freqüentemente ocorre nos casos crônicos.

A classificação quanto à extensão das lesões em tuberculose mínima, moderada e avançada segue os critérios clássicos da National Tuberculosis Association.

O tratamento é feito com SM (1 g/ dia), PAS ( $10 \mathrm{~g} /$ dia $)$ e INH $(400 \mathrm{mg} /$ dia $)$ até o $3 .^{\circ}$ mês; PAS e INH até o $6 .^{\circ}$ mês e INH $(500 \mathrm{mg} /$ dia $)$ até 012.0 mês. As crianças tomam doses proporcionalmente menores e os velhos de mais de 50 anos SM em dias alternados.

Os pacientes comparecem ao Dispensário mensalmente, exceto os Extradistritais de regiões mais distantes que levam drogas

* Médico-chefe do Dispensário de Tuberculose de Golânia - Go. Assistente do Departamento de Medicina Tropical do Instituto de Patologia da UFGo. (Diretor - Prof. William Barbosa).

Recebido para publicaçáo em 10.5.71. 
para 2 ou 3 meses, especialmente após terem negativado a bacterioscopia do escarro e dependendo de suas condições pessoais de comparecer ou não com mais assiduidade ao DT.

A alta por cura é dada após um ano de tratamento se tiver havido cura normal de negativação do escarro (exame feito a cada comparecimento) e melhora clínica e radiológica (abreugrafia a cada 3 meses).

São considerados casos de "Abandono" os faltosos, após mais de 30 dias de interrupção do tratamento.

\section{DISCUSSÃO}

O Dispensário de Tuberculose de Goiânia (Centro de Saúde - Organização de Saúde do Estado de Goiás) é a único órgão de contrôle dispensarial da enfermidade em todo o Brasil Central, excetuado o Distrito Federal. Apenas o município da Capital, com uma área de $1.312 \mathrm{~km} 2$ e uma população estimada em perto de 400.000 habitantes já representaria uma desafiadora sobrecarga à sua atividade, sabendose que a população ideal que deve ser "vigiada" por um dispensário de tuberculose deve situar-se abaixo de 100.000 habitantes.

Além dêstes fatos, grande número de doentes de outras áreas do Estado e de Unidades vizinhas da Federação afluem para esta Capital em busca de recursos médicos especializados, inexistentes nas localidades de origem.

Esta situação determina a existência de um elevado contingente de pacientes extradistritais, sôbre os quais o contrôle do tratamento e medidas preventivas e epidemiológicas (localização, vacinação, tratamento profilático dos comunicantes etc.) são precários e de baixo rendimento.

Mostraremos, nos quadros I, II e III e VII, alguns dados estatísticos do DT de Goiânia, e, a título de ilustração, mostrare-

\section{Quadro I}

PROCEDENCIA DE 619 PACIENTES INSCRITOS EM 1968 (TUBERCULOSE PULMONAR E EXTRA-PULMONAR)

\begin{tabular}{l|c|c}
\multicolumn{1}{c|}{ Procedência } & Distritais & Extra-Distritais \\
\hline Goiás & 196 & $\begin{array}{r}396 \\
13 \\
\text { Bahia }\end{array}$ \\
Outros Estados & & 14 \\
\hline Total & $196(32 \%)$ & $423(68 \%)$ \\
\hline
\end{tabular}

Quadro II

DISPENSARIO DE TUBERCULOSE DE GOIÂNIA

DADOS GERAIS REFERENTES AS ATIVIDADES DESENVOLVIDAS DE JANEIRO DE 1968 A DEZEMBRO DE 1970

\begin{tabular}{|c|c|c|c|}
\hline & 1968 & 1969 & 1970 \\
\hline Abreugrafias & 42.315 & 65.325 & 68.061 \\
\hline Testes de PPD ...... & 1.770 & 7.241 & 5.431 \\
\hline Total de pacientes inscritos ... & 733 & 691 & 813 \\
\hline Casos de tuberculose pulmonar (BAAR + ) & 505 & 462 & 513 \\
\hline 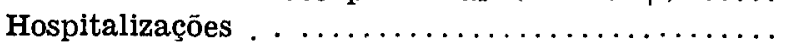 & 229 & 251 & 336 \\
\hline Altas concedidas por cura $\ldots \ldots \ldots \ldots \ldots \ldots$ & 258 & 408 & 416 \\
\hline Abandono $\ldots \ldots \ldots \ldots \ldots \ldots \ldots \ldots \ldots \ldots$ & - & 203 & 242 \\
\hline obitos $\ldots \ldots \ldots \ldots \ldots \ldots \ldots \ldots \ldots \ldots$ & 53 & 36 & 40 \\
\hline Comunicantes examinados & 239 & 298 & 408 \\
\hline
\end{tabular}


Quadro III

DISPENSÁRIO DE TUBERCULOSE DE GOIÂNIA

CLASSIFICAÇÃO DOS PACIENTES NOVOS INECRITOS, QUANTO A EXTENSÃO DAS LESÕES (TUBERCULOSE PULMONAR)

\begin{tabular}{|c|c|c|c|c|c|c|}
\hline \multirow[b]{2}{*}{ Classificação } & \multicolumn{2}{|c|}{1968} & \multicolumn{2}{|c|}{1969} & \multicolumn{2}{|c|}{1970} \\
\hline & N.o & $\%$ & N. ${ }^{\circ}$ & $\%$ & N.o & $\%$ \\
\hline Mínima & 45 & 7,7 & 47 & 8,6 & 33 & 5,3 \\
\hline Moderada & 235 & 40,5 & 188 & 36,2 & 186 & 30,0 \\
\hline Avançada. & 306 & 51,8 & 311 & 55,2 & 402 & 64,7 \\
\hline Total . . . & 581 & 100 & 546 & 100 & 621 & 100 \\
\hline
\end{tabular}

mos dados correlatos de outros Dispensários de Tuberculose, de onde ressaltará logo - regime de intolerável sobrecarga sob o qual vem operando o nosso serviço, o que, aliado a outros fatôres que serão mostrados, explica a obtenção de alguns resultados menos satisfatórios apresentados e que exigem correção inadiável.

O Dispensário-Escola do Serviço Nacional de Tuberculose, no Rio de Janeiro, trabalha com jurisdição sôbre uma área de $9,4 \mathrm{~km} 2$ e uma população de $75.000 \mathrm{ha}$ bitantes (4), condiçōes portanto, edênicas (especialmente do nosso sofrıdo ponto de vista) para a obtenção de ótimos resultados. Este dispensário deve ter também seus pacientes extra-distritais, embora os mais distantes residam provàvelmente em Jacarepaguá ou Niteroi, enquianto que os nossos extra-distritais vivem muitos dêles a centenas de quilômetros e dias de viagem do dispensário de Goiânia. (Quadro IV).

O Dispensário da V Região Administrativa do Rio de Janeiro ( um dos QUATORZE dispensários estaduais da Guana-

Quadro IV

DISPENSÁRIO-ESCOLA DO SNT - RIO DE JANEIRO

MOVIMENTO RELATIVO AO PERIODO DE 1.\%/1/65 A 30/6/67 (30 MESES)

\begin{tabular}{|c|c|c|c|}
\hline Especificação & N.o & $\%$ & Média anual \\
\hline 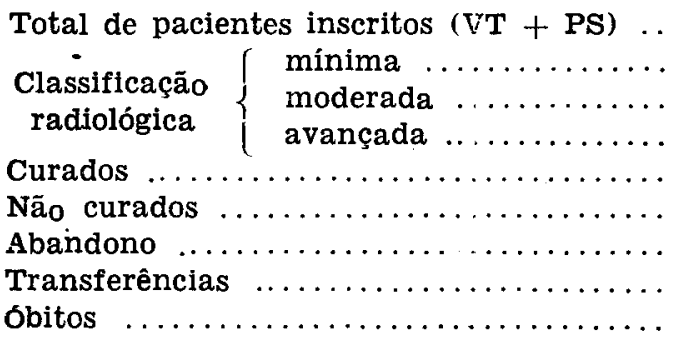 & $\begin{array}{r}913 \\
71 \\
399 \\
443 \\
743 \\
42 \\
63 \\
36 \\
29\end{array}$ & $\begin{array}{r}7,8 \\
43,7 \\
48,7 \\
81,4 \\
4,6 \\
6,9 \\
3,9 \\
3,2\end{array}$ & 365 \\
\hline
\end{tabular}




\section{Quadro V}

SERVIÇO DE TUBERCULOSE DO CENTRO MÉDICO-SANITÁRIO

DA 5. ${ }^{\text {a }}$ REGIÃO ADMINISTRATIVA - RIO DE JANEIRO

1. ${ }^{\circ}$ SEMESTRE DE 1967

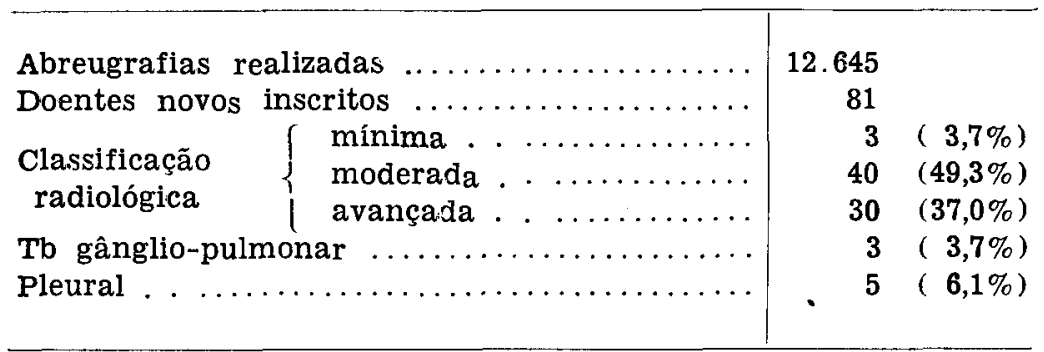

Dados de Pereira da Rocha, 1967 (5).

bara), órgâo de treinamento da Secretaria de Saúde local, serve bem para comparação com o nosso Serviço, especialmente porque o Diretor do Departamento de $\mathrm{Tu}$ berculose đa Guanabara também o considerava "sobrecarregado" $(5,6)$. (Quadro V)
Recentemente a Revista do Serviço Nacional de Tuberculose publicou dados referentes a um grupo de 17 dispensários de vários Estados, cujos números achamos interessante reproduzir. (Quadro VI).

\section{Quadro VI}

MOVIMENTO RELATIVO A 17 DISPENSÁRIOS DE TUBERCULOSE, NO PERIODO DE 1.7.66 A 30.6.67

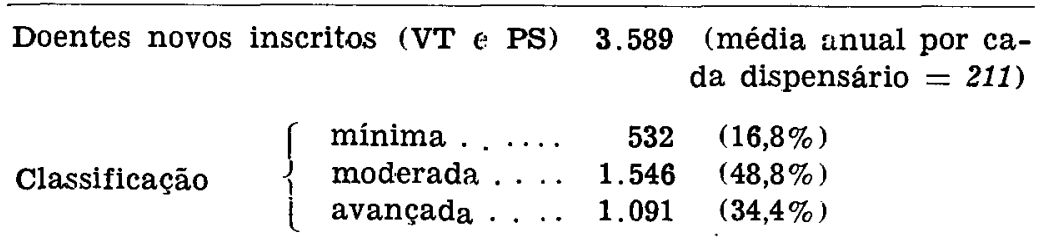

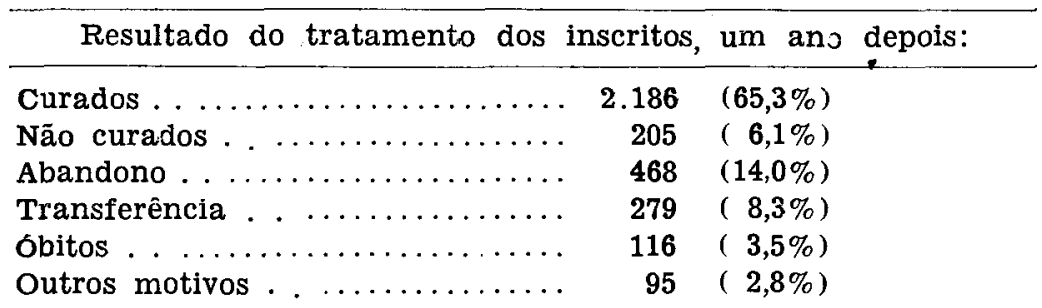

Não foram classificados 420 pacientes que não fizeram exame abreugráfico.

Relação dos Dispensários cujos dados compõem o quadro acima:

Macapá

Manaus

Terezina

Campina Grande

Recife (um dos 5 da cidade)

Maceíó
Aracaju

Brasília (um dos 4 do DF)

Niterói (2 dispensários)

Nova Iguaçu

Nilópolis

Curitiba (2 dispensários)

Florianópolis

Joinvile

Cuiabá. 
Da observação dos dados referidos nos quadros precedentes, algumas conclusões são tranqüilas:

1. - $\mathrm{O}$ volume de trabalho desenvolvido pelo DT de Goiania é sufocante. Pelo menos, apresenta uma produção (em volume, insistimos) igual a quase o dôbro e até o triplo - vide número de pacientes inscritos anualmente - de serviços congêneres.

2. ${ }^{\circ}$ - A composição da massa de pacientes que procuram o serviço apresenta caracteristicas especiais: compõe-se, em quase $70 \%$, de pacientes extra-distritais, sôbre os quais é impossivel qualquer contrôle realmente efetivo e apresenta alta percentagem de doentes em fase avançada da doença, em proporção nìtidamente malor que a apresentada por outros serviços. Verifica-se também, que esta proporção está aumentando de ano para ano (Quadro III). Ora, como aumentaram progressivamente o número de abreugrafias, o número de testes de PPD realizados, o número de comunicantes examinados e o número de inscritos anualmente, isto é, como se fêz um esfôrço cada vez maior para o diagnóstico dos casos de tuberculose e, no entanto aquela proporção aumentou, isto significa que os pacientes estão chegando cada vez mais tarde ao Dispensário.

Esta característica dos pacientes do nosso serviço decorre das razões já con- sideradas: a escassez de recursos, sendo DT o único da região, as enormes distâncias, o baixo nível econômico e sóciocultural da população e outras razões que fazem com que o paciente só procure o órgão em última instância, muitas vêzes em fase terminal da doença, irrecuperável.

o rendimento ou a qualidade do trabalho Dispensarial pode ser avaliado, e em geral é êste o parâmetro utílizado, pela percentagem de altas obtidas do número de pacientes inscritos, após 12 meses de tratamento.

Este rendimento depende, especialmente:

a) - Da continuidade do tratamento, isto é, da regularidade com que os pacientes comparecem ao DT para contrôle e obtenção das drogas. Isto ciepende, por sua vez, da conveniente motivação do paciente para se tratar corretamente, o que é feito nas entrevistas com o médico, a enfermeira e a visitadora (que não temos). Mais ainda, da possibilidade do paciente obedecer às recomendações, de seu nível econômico-cultural etc.

b) - Da porcentagem de casos graves, avançados, de pior prognóstico.

c) - Da porcentagem de pacientes VT e PS em relaçāo aos crônicos, também de prognóstico duvidoso.

Os resultados por nós obtidos no ano de 1968 acham-se referidos no Quadro VII.

Quadro VII

\section{DISPENSÁRIO DE TUBERCULOSE DE GOIÂNIA}

RESUlTADO DO TRATAMENTO DE PACIENTES DE TUBERCULOSE PULMONAR VT E PS, INSCRITOS EM 1968, AVALIADO 12 MESES APÓS

\begin{tabular}{|c|c|c|c|c|c|c|}
\hline \multirow[b]{2}{*}{ Inscritos } & \multicolumn{2}{|c|}{ Distritais } & \multicolumn{2}{|c|}{ Extra Distritais } & \multicolumn{2}{|c|}{ Total } \\
\hline & 167 & $100 \%$ & 331 & $100 \%$ & 498 & $100 \%$ \\
\hline Curados & 95 & 56,8 & 199 & 60,1 & 298 & 59,0 \\
\hline Abandono & 36 & 21,6 & 73 & 22,0 & 109 & 21,9 \\
\hline Transferência . & 12 & 7,2 & 17 & 5,2 & 29 & 5,9 \\
\hline óbitos ...... & 8 & 4,8 & 25 & 7,5 & 33 & 6,6 \\
\hline Outros .............. & 16 & 9,6 & 17 & 5,2 & 33 & 6,6 \\
\hline
\end{tabular}




\section{CONCLUSOEES}

Os dados apresentados e as consideraçōes feitas dão uma idéia do volume e da qualidade do trabalho desenvolvido pelo DT de Goiânia. Computados os óbices e os "handicaps" referidos, é visivel que os resultados por nós obtidos, quanto à qualidade, são inferiores, se bem que, em alguns casos quase comparáveis, aos de outros serviços congêneres, que manuseiam material mais favorável, mais homogêneo e mais controlável, como se conclui dos argumentos apresentados.

Razões de ordem diversa poderiam ainda ser alinhadas para se justificar a situação exposta, como por exemplo, o fato de que o Dispensário-Escola do Rio de Janeiro trabalha com 9 médicos, enquanto que nós contamos apenas com 3 .

A situação entretanto é insustentável e tende a se agravar, pelo aumento da demanda do serviço. Devido ao crescimento populacional, à melhoria das comunicações e dos transportes no Estado, esta demanda acabará por sufocar a capacidade de atendimento do Dispensário, obrigando-o a funcionar como um simples ambulatório de doentes, o que pràticamente já vem ocorrendo. A endemicidade da doença, que seria o fator de equilíbrio do problema se se deslocasse para menos, vem se mantendo nos mesmos níveis nos últimos anos.

A solução do problema residirá, claramente, na criação de novios centros de prevenção e combate à enfermidade, estratè- gicamente situados em munisípios mais populosos do Estado ou em zonas onde a experiência tem indicado serem verdadeiros focos da doença. Citamos para exemplificar: Itumbiara, Céres, Anápolis, Rio Verde e Trindade. A criação de Dispensários nestas cidades, além de mais dois, pelo menos, para a Capital, é inadiável.

Além disto é necessário descentralizar o contróle da doença, distribuindo-o por micro-unidades, localizadas em hospitais gerais e unidades do Serviço de Saúde do Estado, convenientemente distribuidas. Tais micro-unidades seriam apoiadas pràticamente em um serviço de enfermagem, treinado nos Dispensários de Tuberculose, e em um pequeno laboratório para bacterioscopia de escarro, sendo o diagnóstico dos casos novos e contrôle do tratamento feitos apenas por êsse exame. As decisões sôbre hospitalizações e altas, os casos cirúrgicos, os crônicos e resistentes e outros casos-problema seriam referidos à Unidade Dispensarial mais próxima, onde, reavaliados e orientados por médico especialista, teriam a solução adequada.

Este plano econômico de combate à tuberculose em Goiás, já foi por nós exposto (juntamente com outros colegas ligados ao problema) às autoridades da Secretaria de Saúde do Estado (OSEGO) e segue, em linhas gerais, a própria orientação atualmente recomendada pelo Serviço Nacional de Tuberculose, em circulares e editoriais e artigos publicados em sua Revista Oficial $(1,2,3)$.

\section{$S U M M A R Y$}

The author presents statistical data related to the activities of a Dispensary of Tubercslasis undier his direction in Goiânia, Goiás, establishing a panallel with similar aiata from other services. He tries to show the adverse conditions against which the service is acting which greatly difficults its work.

The arguments discussed show that the situation already unfavorable is prone to be worse, needing unpostponable measures suggested by the author.

\section{BIBLIOGRAFIA}

1 - EDITORIAL - Rev. Serv. Nac. Tub. (Brasil) 13: 327, 1969.

2 - EDITORIAL - Rev. Serv. Nac. Tub. (Brasil) 11: 369, 1967.

3 - EDITORIAL - Rev. Serv. Nac. Tub. (Brasil) 12: 217, 1968.

4 - FRAGA, H. et al. - Contrôle do tratamento da tuberculose pulmonar em áreas urbanas do Brasil - Rev.
Serv. Nac. Tub. (Brasil) 13: 329, 1969.

5 - PEREIRA DA ROCHA, E. - Atividades de um dispensário de tuberculose na Guanabara - Rev. Serv. Nac. Tub. (Brasil), 11: 475, 1967.

6 - PEREIRA DA ROCHA, E. - Atividades da luta contra a tuberculose - Rev. Serv. Nac. Tub. (Brasil) 13: 